This is an Author's Accepted Manuscript of an article published in ASIA PACIFIC JOURNAL OF SPORT AND SOCIAL SCIENCE, vol.1, nos.2-3, 2012, copyright Taylor \& Francis, available online at: http://www.tandfonline.com/10.1080/21640599.2012.751170.

\title{
Western men and Eastern arts: The significance of Eastern martial arts disciplines in British men's narratives of masculinity
}

\author{
Alex Channon \\ Department of Secondary Education, University of Greenwich, London, UK \\ Corresponding Author: \\ Dr. Alex Channon, School of Education, University of Greenwich, Mansion Site, Bexley Road, \\ London SE9 2PQ \\ Tel: +44 (0)2083318255 \\ Email: a.g.channon@gre.ac.uk
}




\title{
Western men and Eastern arts: The significance of Eastern martial arts disciplines in British men's narratives of masculinity
}

\begin{abstract}
Previous Western sociological research on Eastern martial arts has identified a tension between 'traditional' Eastern forms of practice and 'modernised' Western methods of training and competition. Particularly, the 'sportisation' of Eastern styles, where combat-centred arts based upon moral philosophies have transformed more or less into competitive activities following Western models of rationalised sport, has been an important theme. However, it is also suggested that Eastern martial arts hold special significance in the West for their seemingly esoteric nature. In this regard, such martial arts are considered significant because they are not 'sports', but rather disciplines with fairly different connotations for practitioners. Drawing on interview data, this paper explores how Western practitioners of Eastern martial arts articulate this difference, principally by examining the place of martial artistry in British men's narratives of masculinity. Comparing themselves favourably to assumed, typical visions of Western sporting masculinity, such men draw upon the imagined uniqueness of their martial arts to construct a sense of moral superiority over other men. In so doing, they contribute to a rejection of what they believe to be 'mainstream' sporting Western masculinity, thus indicating the role that 'alternative' visions of physical culture can play in men's active constructions of gender.
\end{abstract}

Keywords: martial arts, gender, masculinities, Eastern, Western

Eastern martial arts have, over the course of the past century, become increasingly popular in various Western contexts. This paper explores the significance of these fighting arts among a particular group of Western practitioners, discussing the assumed character of 'traditionalist' 1 Eastern arts relative to the place of sport in the construction of masculinity, a long-standing feature of Western physical culture (McKay, Messner \& Sabo, 2000). By drawing on the narrative accounts of several British men experienced in various Eastern martial arts, this paper aims to contribute to debates over the meanings of 'martial arts' in the West, whilst exploring how masculinities are constructed within physical cultural settings.

\section{Arts and sports: contested meanings of martial arts in the West}

Since their first introduction to the West, Eastern martial arts disciplines have tended to be practiced in either traditionally 'Eastern' formats, or somewhat adapted, 'Western' variations (Theeboom, De Knop \& Vertonghen, 2009). These adaptations have come principally as the arts have been disembedded from their 'home' settings, and modified in order to fit within Western physical cultural norms (Krug, 2001). In this regard, the meanings of participation have borne significance through either reflecting and supporting normative Western sporting

\footnotetext{
${ }^{1}$ This term is used to denote Eastern martial arts, such as Japanese jujutsu or Chinese taijiquan, which are passed from one generation of practitioners to the next without significant refinement or adaptation of their curricula, training methods, philosophical underpinnings, etc.
} 
ideologies, or in representing 'alternative' forms of body culture for Westerners (c.f. Villamon, Brown, Espartero \& Gutierrez, 2004).

This process of adoption and appropriation appears throughout the history of such martial arts in the West, which arguably began in the late $19^{\text {th }}$ century when British jujutsu practitioner E.W. Barton-Wright returned from Japan to pioneer the teaching of the art in London (Noble, 1999). In Edwardian Britain, the 'cult of athleticism' and the ideology of 'muscular Christianity', out of which modern Western sports had begun to arise, were key markers of contemporary idealisations of masculinity (Markula \& Pringle, 2006), making for fertile ground for the import of new, and highly effective, forms of hand-to-hand combat (Wolf, 2005). While also holding appeal to a small number of female practitioners of the time (e.g. Looser, 2011), jujutsu was readily seized upon by an eager male audience as a unique new approach to mastering 'the manly arts' of self-defence combat.

This Western cultural zeitgeist, out of which rationalised, competitive sport would emerge as a major, predominantly male pastime, would soon see the adaptation of 'traditionalist' arts into frames of meaning more familiar to Western audiences. Judo, an offshoot version of jujutsu created by the iconic modernist Jigoro Kano (Hamaguchi, 2005), would became the archetypal 'modern', competitive Eastern martial art, following its growth in popularity after World War II under the increasing influence of the globalised, rationalised, competitive Western sporting model (Carr, 1993; Goodger \& Goodger, 1980). Following its 'modernisation', the art became less of a vehicle for philosophical education in distinctly Japanese values, and more of an athletic competition both in the West and in its homeland of Japan (Goodger \& Goodger, 1977; Villamon et al., 2004). Okinawan karate underwent similar transformations. Having been introduced to the West in the mid- $20^{\text {th }}$ century by servicemen who had taken part in the American occupation of Japanese territory during the Second World War (Tan, 2004), karate developed from disparate, localised art forms into a number of rationalised, standardised disciplines featuring technical grading and competitive fighting. This eventually led to the popularisation of 'sport karate' in the 1970s - later called 'kickboxing' - a martial art developed for the purposes of competitive, full-contact sparring popular for its similarities to familiar, masculinised, Western practices, such as boxing (Krug, 2001).

However, not all martial arts were thus transformed, and many 'traditionalist' Eastern disciplines today remain popular in the West. For instance, Jennings, Brown and Sparkes (2010) described wing chun kung fu as a 'secular religion', suggesting that practitioners might train at wing chun to learn about a particular Eastern creed, or that devoted practice of the art may become a religion in its own right. While the religious/philosophical content of these 'traditionalist' pedagogies is often largely the product of 'invented traditions' (Brown, Jennings \& Molle, 2009), these arts continue to hold spiritual and philosophical significance for Western practitioners, which can be a large part of their appeal. Chinese arts such as taijiquan are practiced widely for a range of non-combative, non-competitive reasons, including for learning about Chinese culture, or as a form of physical therapy or meditative exercise, all of which have become increasingly popular in Britain and other Western 
contexts, along with the popularisation of traditional Chinese medicine (Jennings, 2010; Krug, 2001; Ryan, 2008). Meanwhile, various Eastern martial arts continue to be practiced for their purported usefulness in 'real' fighting situations, being popularly taught for the purposes of self-defence (e.g. Angleman, Shinzato, Van Hasselt \& Russo, 2009). They are also advocated as a useful addition to Western physical education programmes due to their inherent inclusivity and capacity for unique learning opportunities, which scholars have suggested makes them valuably different from the typically narrow, 'sporting' content of mainstream pedagogies (Brown \& Johnson, 2000; Levine, 1991; Theeboom \& De Knop, 1999). Furthermore, distinctly Eastern arts continue to appeal as forms of holistic selfimprovement, a solution to the excesses of Western consumerism through ascetic devotion to training and a romantic enthusiasm for what are assumed to be ancient, Oriental 'way(s)' of life (e.g. Polly, 2007; Twigger, 1997).

While writing on contemporary 'traditionalist' practice of Eastern arts in the West rarely foreground connections between martial artistry and masculinity, the same cannot be said for scholarship of today's pre-eminent sporting discipline - mixed martial arts (MMA). The recent emergence of MMA in the West (Sánchez García \& Malcolm, 2010) has involved something of a paradigm shift in the cultural status of martial arts, by relocating them to the heavily masculinised terrain of combative, violent, predominantly male, professional sport (cf. Messner, 1990; Spencer, 2012). Taking its cues from boxing and wrestling, MMA broadcasting typically showcases 'gladiatorial' matches, in which heavily muscled (and almost always male) prize-fighters struggle though what are often bloody contests (Wertheim, 2010). With competitive performance as its mainstay, MMA is situated within a cultural arena largely defined by highly masculinised imagery and discourse (Mayeda \& Ching, 2008), and research into MMA training cultures suggests that masculinity is also an important aspect of practitioners' embodiment (Spencer, 2011), akin to other, similarly framed 'masculine' sports cultures. Further, there is a sense of MMA having challenged the status of 'traditionalist' Eastern arts in the West. Whereas many such styles draw their legitimacy and prestige from the lineage between current teachers and (legendary) past masters (Brown \& Jennings, 2011), contemporary MMA arose as an attempt to dramatically measure the relative worth of various arts via competitive fights between current exponents (Downey, 2007). And as Green (2011) notes, this has challenged the image and status of 'traditionalist' Eastern martial arts in the West, because although arts with Eastern roots are used widely in MMA, many elements associated with the more traditional approaches (e.g. 'internal energies', 'the one-inch punch', etc.) seemingly hold little combative value in relatively deregulated 'cage fights'.

As such, the meanings of 'martial arts' in the West are somewhat contested. Literature on the topic suggests that Eastern styles continue to represent an 'alternative' form of physical culture to 'mainstream' competitive sports, as well as having simultaneously been adapted to fit within this model in numerous ways. In this paper, the assumed uniqueness of 'traditionalist' Eastern martial arts is explored among a sample of male British martial artists, whose perspectives were investigated as part of two studies into the gendered practices among mixed-sex martial arts training cultures. During these studies it emerged that the 
dichotomy between competitive sport and 'traditionalist' approaches to Eastern martial arts was highly meaningful to some men, and in particular served as a vehicle through which they could construct masculine identities in opposition to certain perceived social ideals. Before discussing the research however, a brief account of the perspective on 'masculinity' used here is warranted.

\section{Sport, martial arts, and the construction of male identities}

A major issue in Western sociology of sport literature, the link between masculinity and sport has been well established throughout the history of the discipline (e.g. Anderson, 2009a; Dunning, 1986; Sheard \& Dunning, 1973; Messner, 1990; 1992). Arguably, the role of sport in validating and/or engendering socially valued forms of male identity has been one of the most consistently discussed themes in this field, with 'combat sports' frequently hailed as being especially important in this regard; boxing, for instance, is often described as being considered 'essentially' masculine in Western contexts (Hargreaves, 1997; Woodward, 2004).

The specific association between masculinity and sport, often seen to be inextricably connected to the gendered power relations between different sexual groups, has often been described in terms of 'hegemonic masculinity' (Pringle, 2005), a concept popularised by Connell's $(1987 ; 1995)$ adaptation of Gramscian hegemony theory. In Connell's work, the 'gender order' of a society is said to involve a dominant ('hegemonic') type of masculinity among a number of subordinated styles, where the hegemonic type is that which best supports the superior social position of men over women, as well as a structure of domination among men themselves. While hegemonic masculinity is seen as a socially constructed, changeable formation which varies over time and between places, in recent Western contexts it has tended to be associated with characteristics including muscularity, competitiveness, aggression, emotional stoicism, toughness, endurance, and ultimately, the ability to (physically) dominate others - such as women and 'subordinated' men (Connell, 1995). As such, competitive combat sports, which are more often than not predicated on these characteristics, have proved ideal avenues through which individual men might attempt to approximate this dominant and dominating masculine ideal (e.g. Messner, 1992; Messner \& Sabo, 1990).

However, following critique from sport sociologists and other theorists (e.g. Pringle, 2005; Wetherell \& Edley, 1999), along with attempts at reformulation (e.g. Connell \& Messerschmidt, 2005), the 'hegemony' model, wherein a singular form of masculinity dominates over others in any given context, has been problematised. Instead, scholars have begun advocating greater sensitivity toward the social conditions which produce specific constructions of masculinity (Petersen, 2003), suggesting attention turn to wider sets of influences than simply the power relations between 'hegemonic' and 'subordinated' masculine types. Other theorists have suggested that structural changes in society have led to a broadening of the power and prestige invested in different masculine styles; for instance, 
Anderson (2009b) proposes that the 'orthodox' type of Western masculinity, considered 'hegemonic' by some, is predicated on the cultural ascendancy of homophobia and 'homohysteria' (the fear among heterosexual men of being labelled as homosexual), both of which are now declining in many Western contexts. This social change has led to the concurrent adoption by (heterosexual) men of a wider diversity of masculinities, none of which appears to be 'hegemonic'. This suggests that while specific masculinities may at times appear to be more highly valued than others, categories such as 'hegemonic', 'marginalised' and 'subordinated' (Connell, 1995) do not readily apply, as power is spread more evenly between competing masculine styles (Anderson, 2009b). Recent theory implies, therefore, that masculinity is best viewed as existing in multiple, socially constructed and contestable forms, each of which owes something to its historical background, contemporary cultural settings, and localised significance within specific social groups. Competing masculinities are therefore usefully explored through the social location and cultural conditions of their production, rather than simply how closely they reflect some single, globally acknowledged, 'hegemonic' type.

In this regard, recent research on men and martial arts has begun to address the construction of masculinities from perspectives sensitised to multiple, shifting, and interconnected dimensions of identity (e.g. Abramson \& Modzelewski, 2011; Bar-On Cohen, 2009; Hirose \& Pih, 2010; Holthuysen, 2011; Rhodes, 2011; Spencer, 2012; Wacquant, 2004), revealing that the relationship between masculinity and martial artistry is constructed relative to the specific social and historical contexts within which the activity takes place. Such a social constructionist approach also informs this present study, as the distinction outlined above, between supposedly 'traditionalist' Eastern styles of martial arts and 'mainstream' sports (including 'Westernised' martial arts) is foregrounded in a discussion of the construction of masculinity among a largely middle-class sample of British male martial artists. The ways in which this group perceives themselves compared to others is explored, helping to identify how this differentiation between 'sport' and 'art' feeds into the hierarchal posturing of men whose narratives of masculinity are bound up within it.

\section{Research methodology}

The data informing this paper is drawn from two qualitative studies conducted in the English East Midlands during the years 2007-11. The first of these studies was conducted within a single shaolin kung fu club, involving combined participant observation and interviewing of club members and instructors. The second was a wider study of several different martial arts clubs across the region, based on interviews with a series of long-term practitioners. In addition to these research methods, the studies were informed by the author's personal experiences of martial arts participation, having practiced in both 'sportised' and 'traditionalist' Eastern martial arts disciplines over a combined period of 7 years. 
In total, the studies included 37 different interviewees, comprised of 17 men and 20 women ${ }^{2}$, whose demographic characteristics were identified in terms of age, social class, ethnicity and sexuality. With an age range of 18-43 for the men and 18-32 for the women, the mean ages of both groups were 26 and 24 respectively. Accounting for the level of their educational attainment and current occupation, it is possible to describe the sample as being predominantly 'middle-class'; 32 had gained an academic or vocational degree, or were currently studying for one, and many worked in knowledge-based or specialist skilled jobs (e.g. accountant, school teacher, etc.). In terms of their ethnicities, most of the interviewees self-identified as being White British, although two of the men identified as Black British, while three men and three women identified as British Chinese, one man British Asian and one woman mixed-race (British/Japanese). Finally, all of the interviewees identified as being heterosexual.

Of further note is that these interviewees represented 15 different martial arts clubs and 11 distinctive martial arts disciplines between them, including choi kwang do, judo, jujutsu, karate, kickboxing, kung fu, $\mathrm{MMA}^{3}$, muay thai, taekwondo and taijiquan. However, this is complicated by the fact that interviewees did not all train at the same specific styles of such arts as karate and kung $\mathrm{fu}^{4}$, while almost all of the interviewees had trained at other clubs previously, as well as in other martial arts disciplines. This often meant that interviewees had experiences of training in various 'traditionalist' schools of Eastern martial arts, with some having also trained in 'sportised' or 'Westernised' variants. As such, the sample of interviewees from these two studies is considered to consist of martial arts aficionados, whose collective experiences represent a diverse range of knowledge about training at various martial arts, in both 'traditionalist' and 'sportised' contexts. This makes for a somewhat original approach to the study of Eastern martial arts practitioners in the West, as previous work has tended to centre on singular schools teaching specific disciplines.

Interviewees were selected based on observations and recommendations from others, with 'snowball' sampling in the second study leading through a network of experienced martial artists. Interviewees were prioritised on the grounds of experience, with 3 years' continuous training as a minimum requirement. Topical, semi-structured interviews were used in both studies, which were then transcribed and thematically coded before being analysed. In some

\footnotetext{
${ }^{2}$ While the men's interview data is prioritised in this paper, information on all participants bears disclosing in order to picture some of the diversity of their training environments.

${ }^{3}$ Typically, those training in MMA clubs alternated between styles such as boxing, muay thai, freestyle wrestling and 'Brazilian' jujutsu. However, it was clear through their interviews that they differentiated between their practice and 'straight' adherence to these separate disciplines; lessons in any particular art emphasised techniques useful in competitive, mixed fights above all else. Thus, MMA is considered a fitting label for their discipline, despite consisting of a mix of ostensibly separate styles.

${ }^{4}$ There are numerous forms of these (and other) arts popular in Britain. Karate consists of distinctive styles such as shotokan/wado ryu/kyokushinkai/etc.; kung fu includes wing chun/hung kuen/lau gar/etc.; they tend to differ on training syllabuses, sparring rules, etiquette and philosophy. Although many techniques and pedagogical methods are shared within and between them, schools tend to promote themselves as distinctive from others based on their emphasis of particular aspects.
} 
cases, follow-up interviews were held in order to clarify findings, although the majority of interviewees declined the offer to do so. Following transcription, interviewees' names were changed, using self-selected pseudonyms to protect their anonymity.

\section{Western men and Eastern arts}

The following sections present data drawn from the two studies which pertain to the male interviewees' constructions of masculinity. Principally, these involved value-laden differentiations between themselves and other 'types' of men, which were most often clarified through reference to the meanings of participation in martial arts relative to 'mainstream' Western (combat) sports.

\section{Sport or art? Constructing an hierarchal dichotomy}

Sports have long been associated with exemplifying 'orthodox' types of masculinity in Western societies (Anderson, 2009b), making them an integral part of many Western men's experiences of physical culture. Thus, before explicitly discussing the men's accounts of masculinity, it is worth noting that a perceived dichotomy between the meanings of 'sport', and the 'art' constitutive of martial arts, was central to many of the interviewees' ideas about their participation. In fact, they were often quick to find points of difference from sports when asked to explain what martial arts meant to them as practitioners.

One key element of this differentiation was the purpose of training, and principally the extent to which competition became the focus of the activity. For kung fu instructor Paul:

Paul: To me martial arts are very different to sports because sports are games, like rugby, it's a competition between players... Martial arts are totally different, they are art forms which you use for fighting, it can be competitive but at its core, its real traditions, that's not the purpose of it.

That sports were relatively one-dimensional in their prioritising of competition, compared to the 'real' purposes of martial arts training, was a consistent theme across many of the interviews. Describing these 'real' traditions and purposes often reduced principally to casting martial arts a method for self-improvement. Unlike sporting competition, where the point of reference for one's achievement was the other (competitor/teammate), here the self remained most important. This meant competitive achievements needed to be held in perspective so as not to lose sight of this fundamental purpose of training. According to karateka and former footballer Simon:

Simon: I think if you're winning (karate competitions) you just have to be careful with how good you think you are, it's not like football where the whole point is winning the league... Getting to your own full potential is the whole point of karate training and you don't get there just by beating people in sparring. You need to keep it all in 
perspective and not just be judging it against other people, just trying to be better than the next man. You need to try to be better than yourself.

In this regard, other interviewees described competition as an essentially cooperative, mutually developmental exercise, as martial artists took responsibility for others' learning as well as their own ${ }^{5}$ :

Gavin: The reason why we fight people in competitions is to learn... The only way you can find your weaknesses is by them getting exposed, and when you're against someone, you help them by exposing their weaknesses. That's the point of it really, not about finding out who's the best, it's to help each other learn and grow.

Not being driven by a need to outdo others, along with a far-sighted perspective on the need for on-going mutual and personal development, were key notions of what some interviewees loosely referred to as the 'philosophical side' of martial arts. For some, this compared favourably to earlier sports experiences, such as kung fu practitioner Bob:

Bob: I suppose it's the philosophical side that makes it really different, for me I think (football) was mostly about being the best one out of your mates, making the school team, scoring goals and showing off... Doing martial arts has a lot of philosophical aspects to it... I think (the philosophical side) makes you more interested in being a better person.

Themes such as introspection, self-development, and the co-dependent nurturing of ability fed into the interviewees' conceptualisations of martial arts as 'philosophical', as the activities performed in day-to-day training and competition were rationalised as part of a broader quest to develop the self in diverse ways ${ }^{6}$. Compared to characterisations of 'sport' as driven solely by competitive performance, this was important in substantiating a narrative which implicitly cast 'traditionalist' martial arts practices as more diverse, holistic and thus valuable pursuits than sporting alternatives (cf. Brown \& Johnson, 2000), which helped practitioners become 'better' people (cf. Buckler, 2010).

Besides the purposes of training, combative 'realism' was another major point of differentiation between sport and art. The fact that martial arts were concerned with learning how to fight was an important topic, particularly when interviewees discussed the differences between 'traditionalist' and 'sportised' styles, wherein they often questioned the authenticity

\footnotetext{
${ }^{5}$ See Spencer (2011) for a discussion of the cooperative and competitive dimensions of sparring as an exercise in either 'cultivation' or 'negation' of the other.

${ }^{6}$ Very few of the interviewees elaborated on the supposed 'philosophical side' of Eastern martial arts in ways which explicitly revealed knowledge of any particular Eastern martial philosophy, such as 'Bushido' (Chan, 2000), 'Budo' (Villamon et al., 2004), 'Wu Wei' (Brown \& Johnson, 2000), etc. However, that such martial arts had a 'philosophical side' was nevertheless important in their narratives, as was the fact that such an aspect made these arts' practice and, by extension, their practitioners, somewhat unique.
} 
of combat sport fighting techniques. This formed a key basis for the differentiation of 'sport' and 'art' for many practitioners:

Lee: $\quad$ Some martial arts you probably see as sports, like probably kickboxing, or Western boxing, it's sporty, but karate and kung fu are not, they're based on actual fighting arts, real fighting. So they're not really sports.

Particularly, the rule-bound nature of competitive sparring was argued to be a constraining factor which taught martial artists to preclude the most effective fighting moves and encourage tactics inappropriate for 'real' fights. Somewhat ironically, this was a criticism often made of contemporary MMA, as well as competitive sparring within 'traditionalist' styles (cf. Downey, 2007). In contrast, it was often felt that some of the more abstract methods of 'traditionalist' arts, such as repeated practice of forms $/ \mathrm{kata}^{7}$, were more useful, by helping practitioners habituate their art's most lethal techniques. Kung fu and taijiquan instructor Kevin told how:

Kevin: There is lots of ground fighting in MMA competitions... (but) it's suicide to go down in a street fight, you'll have your head kicked in by (your opponent's) mates.

AC: $\quad$ So are kung fu competitions more realistic?

Kevin: The problem we have is that there's no punching to the head and no kicking below the belt, and that's for safety, so it's nothing like real fights either... The forms have throat punches and knee-joint kicks, we do it because that's what works, that's the real kung fu we want you to fight with. Competitions are not kung fu because there's no reality in the rules. If there's rules it's not real fighting.

The abilities of combat sport athletes, and in particular the implicit claims of the MMA movement to represent an 'ultimate' form of fighting (Downey, 2007; Wertheim, 2010), were implicitly positioned as an exercise in self-deception, as sporting contests were seen to remain bound by rules and norms which narrowed the possibilities of fights, restricting practitioners' habituated fighting abilities in important ways ${ }^{8}$. In the face of a perceived shift away from the abstract training of 'traditionalist' Eastern styles brought on by the 'sportisation' of martial arts, many interviewees defended such methods (e.g. choreographed forms consisting of throat/eye/groin strikes) in terms of their capacity to both prepare for and contain the 'real' violent potential of their arts. Therefore, as well as making practitioners 'better' people than sports were able to, such martial arts were also thought to make them more effective fighters, and this combination of morality and combative ability held some significance for their constructions of masculinity.

\footnotetext{
7 'Forms' or 'kata' are choreographed series of techniques typically constitutive of various Eastern martial arts curricula, often performed alone or in pairs. As pre-determined sequences of movements, they differ quite markedly from free-flowing sparring practice.

${ }^{8}$ In stark contrast to the deregulated 'cage fights' of the early 1990s, today's MMA organisations adopt far more stringent regulations (e.g. The UFC, 2012). Elsewhere, competitive arts such as taekwondo and judo rely on point-scoring systems which are largely symbolic of 'real' violence, such that victorious competitors rarely incapacitate their opponents in any meaningful sense.
} 


\section{Martial arts and 'being violent'}

Typically then, the interviewees' attempts at outlining what constituted a 'real' martial art involved using sports (and sportised martial arts) as a reference point for determining what 'real' martial arts were not. They also used similar strategies when asked about masculinity. This often involved a forthright rejection of the 'masculine' characteristics believed to be associated with practitioners of other (combat) sports, and concurrent self-definition in contrast to them. As such, while the interviewees were often reticent to talk about themselves as being 'masculine' in explicit terms, their self-positioning in opposition to other masculine archetypes became a method for constructing a masculinity against an assumed social ideal, which they often connected with sports.

The first of these antithetical characteristics was an association between combat sports and violence, which was in some cases explicitly connected to perceived cultural differences between East and West ${ }^{9}$. Discussing adaptations of Eastern martial arts, Gavin, who practiced a 'traditionalist' kung fu style as well as having taken MMA classes, described his understanding of the 'Westernisation' of traditional Eastern arts principally in terms of violence, sport and masculinity:

Gavin: Well what they've done, they've taken Eastern martial arts, brought it over to the West, and they've kind of made it more violent, I think... And I think in a way you can kind of distinguish the two cultures, in the East (martial arts is) more of a way of life or a philosophical thing, but in the West people see it as more of a violent sport thing. Who can be the alpha male, that kind of thing, and that's why it's so popular on TV.

For many interviewees, the 'types' of men who participated in mock-combative sports like rugby, or in competitive fighting disciplines such as boxing or MMA, were thought to fit into the model outlined by Gavin; these sports represented an idealised 'Western' masculinity which celebrated men's potential for violence. Such men were considered to be prone to, or enjoy, 'being violent', as fighting formed a constitutive element of their masculinity by enabling them to assert dominance over others, thus becoming the 'alpha male' (cf. Mayeda \& Ching, 2008). According to kung fu practitioner Lee, this stood in stark contrast to the attitude of the idealised martial artist, for whom self-knowledge abated the need to engage in violent dominance struggles with other men:

Lee: The difference is, well if somebody said something to them, if they were a rugby player, they'd think, "he's just insulted me, I've got to prove myself now as a man, I've got to smash him in". But a martial artist, it goes over your head, whatever, doesn't matter what people think of you... Everything you do is more controlled when you're a martial artist, and especially with violence... you know what you can

\footnotetext{
${ }^{9}$ See Hirose and Pih (2010) for an elaborate, if theoretical description of Western and Eastern masculinities within MMA cultures.
} 
do and don't need to prove anything, you can be quietly confident and that's enough to make you, sort of a secure person, it's being the bigger man.

Fighting to 'prove' oneself was thereby criticised as betraying character flaws such as insecurity and lack of control, which undermined rather than proved masculinity. Despite this criticism however, being able to fight was still highly valued by all of the men, as avoiding unnecessary violence did not preclude avoiding violence altogether. A perception of the violent and unpredictable nature of contemporary society made being capable of fighting an important life skill for some of the interviewees, imbuing the practice of martial arts with its own moral justification. In this regard, the reservation of fighting ability for nobler uses, such as preserving one's safety, was a recurrent theme, as was the paternalistic imperative of being able to provide such protection for one's family. Importantly though, rather than simply prepare them to win fights, martial arts taught as much about the art of not fighting as they did about fighting itself. According to kung fu instructor Jack:

Jack: If I was in a threatening situation and my family was in trouble, I would do everything to avoid violence, to protect them... But if I absolutely had to fight, that's when I would fight, to protect them. I'm not a violent person, I hate violence... but I would fight to protect them, yes.

AC: $\quad$ And do you think learning kung fu will make a difference in that?

Jack: After 15 years (of training) I'd hope so! But no, it does, it does make a difference, in knowing about when to fight and when not to... It's mostly about knowing how to hold yourself in that situation without resorting to violence... So it mostly helps me to not fight.

The simultaneous capacity for and avoidance of violence was also frequently cited when discussing competitiveness and fighting, and the difference between martial artists and combat sport practitioners. Again, the perceived desire to 'prove' something became a clear point of distinction, as jujutsu and kung fu practitioner David described:

David: I remember talking to someone who said he was a cage fighter, and he told me if kung fu was (so effective) then I should try to fight him, see how my martial art stands up in the cage. I told him that we would never do that because it wasn't what the art is for, it's not right to use it for that... We can do things that will really hurt someone and you can't be doing that to people just for like, proving you're good or winning a competition or something.

Andy, who had practiced 'traditionalist' martial arts for many years before coaching at an MMA gym, elaborated on this distinction with explicit reference to the different masculinities associated with fighting arts and combat sports:

Andy: I don't need to prove anything to anyone, I do (MMA) for the art of it. So (I'm) more of an artist, in my eyes, than a fighter... And the contrast with the guys (at the MMA gym)... The way they behave just seems pretty extreme, so I see myself as 
even less like them. I don't see myself as less manly (because of this), but less of what (they) think is manly.

In these ways, knowing that they were able to fight, whilst consciously choosing not to unless absolutely necessary, indicated the martial artists' moral ideals concerning violence and its link to differently valued forms of masculinity. Their abilities were sacred in that they were only to be used for self-defence, and were not for personal aggrandisement through sporting victories or violent fights, as was seen to feature within others' idealisations of manliness. And this distinction would, for some interviewees, serve as evidence of a moral superiority over those (imagined) other men - such as the rugby players, boxers, or 'cage fighters' they described - for whom fighting was thought to be a means of proving one's masculinity by violently dominating or intimidating others. Former kung fu practitioner and kickboxing instructor Amir told how:

Amir: (Eastern) martial arts generally, they produce grounded people, I've always said that, and my (kickboxing) club here, I do it the same way, teach them to just be relaxed, chilled out, decent guys... If you met them in the street you'd not know they were fighters, and that's the thing... it just produces grounded people, whereas other sports like boxing, well it produces thugs... I've seen guys go to boxing and come out as absolute violent thugs, always looking to get into fights, you know, "you better watch it, I'm a boxer", just thugs.

\section{Sexuality, women, and mixed training}

As well as violence, sexuality and relations with women were other themes which emerged as important points of distinction for martial artists. In this regard, male body image was discussed, wherein recreational bodybuilders became the target of some criticism. Cast as the dupes of a dictated, media-driven masculine ideal (Stibbe, 2004), men who deliberately trained to project a powerful, (hetero)sexualised, masculine image were identified as superficial and shallow when compared to the martial arts man, who invested functional abilities into his body ${ }^{10}$ :

Lee: $\quad$ That whole mainstream gym culture, it's making your body look a certain way, look how society says it should be, Men's Health (magazine) and that. It's not about what your body can do but how it looks... You don't use your body, it's just to impress girls, to look good for the beach, saying "I've got a better body than you"... I've always thought my body should be, I think, practical, it can do things... It's not about what you look like to others but about what you can do, so I train for that and not for looks.

Once again, the notion of 'proving' something to others - in this case, projecting a powerful embodiment of male heterosexuality - was central to the form of masculinity which was criticised and rejected by the interviewees. As Jack put it:

\footnotetext{
${ }^{10}$ See Tivers (2011) for a discussion of masculinity, functional ability and 'posing' among strength athletes and bodybuilders.
} 
Jack: I think if you've got something to prove all the time then you're not comfortable in your own skin, and to be honest with you I've never liked men who are always out to prove something... all the bluster and showboating of like, bodybuilder types, image-focused... Going strutting like a peacock to get (women's) attention, it's all a bit childish I think.

As well as the apparently narcissistic, sexual imperative driving image-based, bodybuilding male gym culture, some interviewees were also critical of the misogynistic forms of heterosexuality sometimes associated with male athletes (Messner, 2002). In this regard, Andy distanced himself - and, implicitly, 'traditionalist' martial arts - from the behaviours of some the competitive MMA fighters whom he had trained:

Andy: I've got a couple of groups of guys in this club who are proper lads, and I have to travel with them sometimes, and it's made me see how I'm totally not like them at all. I was in America with them recently and they were shagging everything, they've got girlfriends, fiancées, pregnant girlfriends even, and they're shagging everything... talking about girls horribly, being really nasty to them physically and stuff when they're with them... I dunno, do other guys consider that manly? But I'm just like, I'm nothing like them whatsoever, I've always been a bit off the mainstream... I like girls, I just think all of this shagging around is very seedy and I won't be a part of it.

AC: $\quad$ And do you see this a lot in martial arts?

Andy: For (competitive MMA) fighters I would say it happens a lot... But not that much outside it, not in karate, not in jujutsu, that's more of a family thing... (These fighters' behaviour) is just like footballers, you know, flash cars, shagging, living the life... it's not the same for regular martial artists.

With professional male athletes' sexual misadventures frequently reported in the British press, stereotypes of promiscuous, hyper-heterosexual sportsmen - and particularly footballers - were not lost on men such as Andy. This then fed into the construction of his own heterosexuality, by favourable comparison to the distasteful type of man associated with the 'mainstream'. By way of contrast, the typical 'family' setting of Eastern martial arts training cultures carried a more morally wholesome image, which men such as Andy were keen to identify with.

While more broadly discussing relations between the sexes, the interviewees, who had experience of training in such 'family-friendly' settings, described training experiences in relatively integrated environments as having impacted upon the ways in which they related to women. The ubiquity of sex segregation throughout much of Western sport has previously been identified as supporting inequitable gender relations in various Western contexts, given that segregated sports participation tends to re-affirm conceptions of male physical 'supremacy' (e.g. McDonagh \& Pappano, 2008) as well as foster misogynistic male homosocial bonding (Messner, 1992). However, for most of the interviewees, training in sexintegrated settings, as well as women's participation in Eastern martial arts generally, were 
both considered 'normal' - if markedly different to other sports they had tried. For some, this was explained as an effect of an historical legacy of women warriors who, in the alleged (and perhaps legendary) history of Eastern martial arts, had played pivotal roles in said arts' development, such as in the origins of wing chun kung fu:

David: I think there is a history of (women's involvement), because traditionally in Chinese kung fu, there are some styles like wing chun for example, it was created by a woman, designed for women... So women have always been in (Eastern) martial arts, and especially wing chun, well it is really popular in lots of countries and it was invented by a woman so I guess (women's involvement) is quite normal.

The female-friendly image of Eastern martial arts was compared with 'Western' variations by interviewees such as kung fu instructor and former karate practitioner Steve, who voiced doubts over the inclusion of women in 'Westernised', ostensibly more 'masculine' disciplines. This was described as an effect of the sports' image, as well as a practical focus on supposedly male attributes, such as muscularity and physical strength, which could prevent women from becoming involved (c.f. Theberge \& Birrell, 1994):

Steve: Styles like boxing, MMA... I think they are more manly because there's more emphasis on strength, (also) wrestling is like that, the traditional Western styles I think of like that, you don't get many women doing them because they seem more manly (than Eastern styles), that's their image, it's for big, muscular men.

As well the contrasting image between 'traditionalist' and Westernised styles, the embodied experience of training with women could lead men to learn about women's abilities, and relate to women physically, in relatively unique ways, such as through the practice of mixedsex sparring. This somewhat exceptional experience was thought by many of the men to have had an effect on their perceptions of women ${ }^{11}$ :

Jack: I fought against a girl I knew in my club, and it didn't make any difference to me personally that she was female because I knew what she was capable of. If I didn't take her seriously, treat her the same (as men in sparring), she'd kick me in the head, she'd hurt me... (this experience) forces you to look at women differently.

With reference to historical precedent as well as their own embodied experiences of training alongside women, the interviewees thus frequently cited their participation in Eastern martial arts as having impacted on their perspectives on fighting, gender, and sex difference (Channon, 2012). The assumed uniqueness of Eastern martial arts played a part in regulating interviewees' narratives of relations between the sexes, contributing to their understanding of gender through the often explicit acceptance of women as equal training partners, legitimised within the cultural norms of their martial arts (see Guérandel \& Mennesson, 2007).

\footnotetext{
${ }^{11}$ See Anderson (2008) for a discussion of mixed-sex cheerleading practice and changes in men's
} attitudes towards female athletes. 
In sum, the interviewees' articulations of sport and martial arts opened up opportunities to describe their masculinity in opposition to what were believed to be the characteristics of a 'mainstream' version of manliness. The masculinity of the martial artist was thus defined against an apparently 'typical' form of 'Western', sporting masculinity, which was predicated on the practice of sport as a means of publicly 'proving' one's masculine superiority. This included such things as engaging in performance-driven competition; acts of unnecessary violence; training to have a 'better body' than others; or through the exclusion and/or sexual denigration of women. By way of contrast, Steve suggested that:

Steve: (Men) who do martial arts... they don't go around wearing it on their sleeves, "I do kung fu", that sort of thing. They're more subdued about it... Yeah, I think a real man isn't into superficial things... I guess a real man is someone who's respectful of everyone around him, accepting (other) people, not really into all that masculinity stuff.

\section{Discussion and concluding thoughts}

This paper has sought to add to current scholarship concerning the role of physical cultures in the construction of masculinities. In this regard, what has not been attempted is a direct comparison between 'Western' and 'Eastern' masculine styles, or between fixed masculinities associated with specific sporting activities. Rather, the role played by the perceptions and assumptions of Western men training at Eastern arts has been examined, allowing the significance of Eastern martial arts in Western men's discursive constructions of masculinity to surface. Thus, while the definitions of 'sport' offered by the interviewees were largely reductive and over-simplified, as were their idealisations of the unique histories and philosophies of 'traditionalist' or 'real' Eastern martial arts, these characterisations are telling given that they helped to form the basis for the interviewees' constructions of gender. Whether their claims about 'sports', 'arts', 'traditions', 'the West' or 'the East' are accurate in any generalizable sense is, therefore, relatively unimportant compared to what they revealed about the men's strategies for constructing a particular form of masculinity.

In making sense of these strategies, the concept of multiple, socially constructed and competing masculinities is useful in framing the interviewees' narratives of manliness, sport and martial artistry. It appears that characteristics associated with a dominant and dominating 'type' of manliness, predicated on proving oneself through being violent, achieving a socially valued 'masculine' physique, being driven to beat others, and excluding or sexually exploiting women, was associated with 'other' types of men involved in supposedly 'mainstream' sports. While sometimes explicitly described as being 'Western' in character, the interviewees principally employed these conceptions of masculinity as a discursive device for demonstrating which types of men they were not. Taken within the context of the struggle over the meanings of martial arts, the men's strategy of contrasting the differences between sport and art involved devaluing the sporting model whilst criticising this type of masculinity. Thus, the men's perceptions of the 'true' meanings of Eastern martial arts, relative to those of 
Western sports, became a device for their active construction of a resistive position within a hierarchy of masculine styles.

Paraphrasing Wetherell and Edley (1999), Connell and Messerschmidt (2005: 840) state that "ironically... one of the most effective ways of 'being a man' in certain local contexts may be to demonstrate one's distance from a regional hegemonic masculinity". In this regard, 'traditionalist' Eastern martial arts provided a framework around which to substantiate and defend a particular vision of masculinity, which was cast as morally superior to the otherwise normative alternative associated with Western sport - a more or less 'toxic' masculine archetype (Connell \& Messerschmidt, 2005) bearing close resemblance to that often described as 'hegemonic masculinity' in previous research into Western sports cultures (e.g. Light \& Kirk, 2000; Messner, 1992; Messner \& Sabo, 1990; see also Pringle, 2005). It is therefore possible to theorise the men's constructions of masculinity as resistive of this perceived social ideal, thus evidencing the lack of hegemony which this 'orthodox' type held over them (Anderson, 2009b). Rejecting this model, they actively formulated their own sense of identity in opposition to its characteristics, and through this example they demonstrated an agentic contestation of competing masculine styles through the discursive possibilities provided by the physical cultural space of Eastern martial arts.

One criticism of this research would be that the extent to which the men's participation in Eastern martial arts is responsible for their having adopted these positions is not knowable from the data gathered here. Indeed, there are likely to be other factors at work in these men's articulations of masculinity; the predominantly middle-class character of the sample, as well as the men's British nationality and heterosexuality, must all be expected to be of relevance in this regard, as too the cultural context of contemporary Britain, wherein previously prevailing 'masculine' norms such as homophobia and 'homohysteria' are in decline (Anderson, 2009b). As such, the findings cannot be generalised to all Western men, or seen as unique to Western men training at Eastern arts. However, it is also important to note that the interviewees' own accounts focused little on their place within particular demographic groups (class, nationality, ethnicity, sexuality, etc.) nor wider prevailing cultural norms; what mattered more was their identity as 'real' martial artists relative to what they believed about male practitioners of 'other' sports. This was, ultimately, the basis for their differentiation from orthodox images of masculinity.

What remains to be seen then, is how this differentiation is patterned beyond the immediate narratives of practitioners. In this regard, large-scale surveys exploring the demographic characteristics of 'traditionalist' Eastern martial arts practitioners in Britain, as well as other Western contexts, could help locate the place of these arts within prevailing social structures such as class or ethnicity in contemporary, diverse and stratified Western societies. Further, comparative research between subcultural groups involved in sport- or art-based athletic disciplines, particularly involving participants drawn from similar social backgrounds, would also help elaborate on the apparent distinctions between these physical cultural settings whilst partially controlling for demographic variables. While a focus on men and masculinity may be of some use in this endeavour, alternative theoretical approaches and substantive foci may 
also be of use in exploring the contemporary significance of Eastern martial arts among Western practitioners.

\section{References}

Abramson, C.M. \& Modzelewski, D. (2011). Caged morality: Moral worlds, subculture, and stratification among middle-class cage-fighters. Qualitative Sociology, 34, 143-175. doi: $10.1007 / \mathrm{s} 11133-010-9175-8$

Anderson, E. (2008). "I used to think women were weak": Orthodox masculinity, gender segregation, and sport. Sociological Forum, 23, 257-280. doi: 10.1111/j.15737861.2008.00058.x

Anderson, E. (2009a). The maintenance of masculinity among the stakeholders of sport. Sport Management Review, 12, 3-14. doi: 10.1016/j.smr.2008.09.003

Anderson, E. (2009b) Inclusive masculinity: The changing nature of masculinities. London: Routledge

Angleman, A.J., Shinzato, Y., Van Hasselt, V.B. \& Russo, S.A. (2009). Traditional martial arts versus modern self-defense training for women: Some comments. Aggression and Violent Behaviour, 14, 89-93. doi: 10.1016/j.avb.2008.12.001

Bar-On Cohen, E. (2009) Survival, an Israeli ju jutsu school of martial arts: Violence, body, practice and the national. Ethnography, 10, 153-183. doi: 10.1177/1466138109106300

Brown, D. \& Jennings, G. (2011). Body lineage: Conceptualising the transmission of traditional Asian martial arts in the West. STAPS: Revue Internationale des Sciences du Sport et de l'Education Physique, 32, 61-72. Retrieved from: http://cat.inist.fr/?aModele=afficheN\&cpsidt=24628833

Brown, D., Jennings, G. \& Leledaki, A. (2008). The changing charismatic status of the performing male body in Asian martial arts films. Sport in Society, 11, 174-194. doi: 10.1080/17430430701823414

Brown, D., Jennings, G. \& Molle, A. (2009). Exploring relationships between Asian martial arts and religion. Stadion, 35, 47-66. Retrieved from: http://www.academiaverlag.de/titel/69554.htm

Brown, D. \& Johnson, A. (2000). The social practice of self-defense martial arts: Applications for physical education. Quest, 52, 246-259. Retrieved from: http://www.old.li.suu.edu/library/circulation/Lyons/pe6070blSelfDefenseMartialArtsSp09. pdf

Buckler, S. (2010). Sects and violence: Development of an inclusive taxonomy to hermeneutically explore the histo-philosophical motivators for the inception and development of the martial art, wing chun kuen. (Doctoral dissertation, Coventry University in collaboration with the University of Worcester, UK). Retrieved from: http://eprints.worc.ac.uk/1033/

Carr, K.G. (1993). Making way: War, philosophy and sport in Japanese judo. Journal of Sport History, 2, 167-188. Retrieved from: http://judoinfo.com/pdf/1993jsh.pdf 
Carruthers, A. (1998). Kung fu fighting: The cultural pedagogy of the body in the Vovinam Vietnamese martial arts school. Australian Journal of Anthropology, 9, 45-57. Retrieved from: http://cat.inist.fr/?aModele=afficheN\&cpsidt=2032109

Chan, S. (2000). The construction and export of culture as artefact: The case of Japanese martial arts. Body \& Society, 6, 69-74. doi:_10.1177/1357034X00006001005

Channon, A.G. (2012). Way of the discourse: Mixed-sex martial arts and the subversion of gender (Doctoral dissertation, Loughborough University, UK). Retrieved from: http://hdl.handle.net/2134/9756

Connell, R.W. (1987). Gender and power: Society, the person and sexual politics. Cambridge: Polity

Connell, R.W. (1995). Masculinities. Cambridge: Polity

Connell, R.W. \& Messerschmidt, J.A. (2005). Hegemonic masculinity: Rethinking the concept. Gender \& Society, 19, 829-859. doi: 10.1177/0891243205278639

Downey, G. (2007). Producing pain : Techniques and technologies in no-holds-barred fighting. Social Studies of Science, 37, 201-226. doi: 10.1177/0306312706072174

Dunning, E. (1986). 'Sport as a Male Preserve: Notes on the Social Sources of Masculine Identity and its Transformations'. Theory, Culture and Society, 3, 79-90. doi: $10.1177 / 0263276486003001007$

Espartero, J., Villamon, M., and Gonzalez, R. (2011) Japanese martial arts: Body practices that represent their cultural identity. Movimento 17(3): 39-55. Retrieved from: http://seer.ufrgs.br/Movimento/article/view/21569/17736

Goodger, B.C. \& Goodger, J.M. (1977). Judo in the light of theory and sociological research. International Review of Sport Sociology, 12(2), 5-34. doi: 10.1177/101269027701200201

Goodger, B.C. \& Goodger, J.M. (1980). Organisational and cultural change in post-war British judo. International Review for the Sociology of Sport, 15, 21-48. doi:10.1177/101269028001500102

Green, K. (2011). It hurt so it is real: Sensing the seduction of mixed martial arts. Social and Cultural Geography, 12, 377-396. doi: 10.1080/14649365.2011.574796

Guérandel, C. \& Mennesson, C. (2007). Gender construction in judo interactions. International Review for the Sociology of Sport, 42, 167-186. doi: $10.1177 / 1012690207084750$

Hamaguchi, Y. (2005). Innovation in martial arts. In J. Maguire \& M. Nakayama (Eds.), Japan, sport and society: Tradition and change in a globalizing world (pp.7-18). London: Routledge.

Hargreaves, J. (1997). Women's boxing and related activites: Introducing images and meanings. Body \& Society, 3(4), 33-49. doi: 10.1177/1357034X97003004002

Hirose, A. \& Pih, K.K. (2010). Men who strike and men who submit: Hegemonic and marginalized masculinities in mixed martial arts. Men and Masculinities, 13, 190-209. doi: 10.1177/1097184X09344417

Holthuysen, J. (2011). Embattled identities: Constructions of contemporary American masculinity amongst mixed martial arts cagefighters (Doctoral dissertation, Arizona State University, US). Retrieved from:

http://129.219.247.59/attachments/56563/content/Holthuysen_asu_0010E_10614.pdf. 
Jennings, G. (2010). Fighters, thinkers and shared cultivation: Experiencing transformation through the long-term practice of traditionalist Chinese martial arts (Doctoral dissertation, University of Exeter, UK). Retrieved from: http://hdl.handle.net/10036/116974.

Jennings, G.B., Brown, D. \& Sparkes, A.C. (2010). 'It can be a religion if you want': Wing Chun Kung Fu as a secular religion. Ethnography, 11, 533-557. doi: $10.1177 / 1466138110372588$

Krug, G.J. (2001). At the feet of the master: Three stages in the appropriation of Okinawan karate into Anglo-American culture. Cultural Studies $\leftrightarrow$ Critical Methodologies, 1, 395410. doi:_10.1177/153270860100100401

Levine, D.N. (1991). Martial arts as a resource for liberal education: The case of Aikido. In M. Featherstone, M. Hepworth \& B. Turner (Eds.), The body: Social process and cultural theory (pp.209-224). London: Sage

Light, R. \& Kirk, D. (2000). High school rugby, the body and the reproduction of hegemonic masculinity. Sport, Education and Society, 5, 163-176. doi: 10.1080/713696032

Looser, D. (2011). Radical bodies and dangerous ladies: Martial arts and women's performance, 1900-1918. Theatre Research International,36, 3-19. doi: $10.1017 / \mathrm{S} 0307883310000684$

Markula, P. \& Pringle, R. (2006). Foucault, sport and exercise: Power, knowledge and transforming the self. London: Routledge

Mayeda, D. \& Ching, D. (2008). Fighting for acceptance: Mixed martial artists and violence in American society. Lincoln: iUniverse

McDonagh, E. \& Pappano, L. (2008). Playing with the boys: Why separate is not equal in sports. New York: Oxford University Press

McKay, J., Messner, M. \& Sabo, D. (2000). Masculinities, gender relations and sport. London: Sage

Messner, M. (1990). When bodies are weapons: Masculnity and violence in sport. International Review for the Sociology of Sport, 25, 203-220. doi: 10.1177/101269029002500303

Messner, M. (1992). Power at play: Sports and the problem of masculinity. Boston: Beacon Press

Messner, M. (2002). Taking the field: Women, men and sports. Minneapolis: University of Minnesota Press

Messner, M. \& Sabo, D. (Eds.). (1990). Sport, men, and the gender order: Critical feminist perspectives. Champaign: Human Kinetics

Noble, G. (1999). W. Barton-Wright (1860-1951) and the eclectic art of Bartitsu. Journal of Asian Martial Arts, 8(2), 50-61. Retrieved from: http://www.journalofasianmartialarts.com/Asia/W.-Barton-Wright-1860-1951-theEclectic-Art-of-Bartitsu/flypage_articles.tpl.html

Petersen, A. (2003). Research on men and masculinities: Some implications of recent theory for future work. Men and Masculinities, 6, 54-69. Doi: 10.1177/1097184X02250843

Polly, M. (2007). American shaolin: One man's quest to become a kungfu master. London: Abacus 
Pringle, R. (2005). Masculinites, sport, and power: A critical comparison of Gramscian and Foucauldian inspired theoretical tools. Journal of Sport and Social Issues, 29, 256-278. doi: $10.1177 / 0193723505276228$

Rhodes, J. (2011). Fighting for 'respectability': Media representations of the white, 'working class' male boxing 'hero'. Journal of Sport and Social Issues, 35, 350-376. doi: $10.1177 / 0193723511426291$

Ryan, A. (2008). Globalisation and the 'internal alchemy' in Chinese martial arts: The transmission of taijiquan to Britain. East Asia Science, Technology and Society: an International Journal, 2, 525-543. doi: 10.1007/s12280-009-9073-x

Sánchez García, R. \& Malcolm, D. (2010). Decivilizing, civilizing or informalizing? The international development of mixed martial arts. International Review for the Sociology of Sport, 45, 39-58. doi: 10.1177/1012690209352392

Sheard, K. \& Dunning, E. (1973). The rugby football club as a type of 'male preserve': Some sociological notes. International Review for the Sociology of Sport, 8(3), 5-24. doi: $10.1177 / 101269027300800301$

Spencer, D.C. (2011). Ultimate fighting and embodiment: Violence, gender and mixed martial arts. London: Routledge

Spencer, D.C. (2012). Narratives of despair and loss: Pain, injury and masculinity in the sport of mixed martial arts. Qualitative Research in Sport, Exercise and Health, 4, 117-137. doi: 10.1080/2159676X.2011.653499

Stibbe, A. (2004). Health and the social construction of masculinity in Men's Health magazine. Men and Masculinities, 7, 31-51. doi: 1 0.1177/1097184X03257441

Tan, K.S.Y. (2004). Constructing a martial tradition: Rethinking a popular history of karatedou. Journal of Sport \& Social Issues, 28, 169-192. doi:10.1177/0193723504264772

Tivers, J. (2011). 'Not a circus, not a freak show': Masculinity, performance and place in a sport for 'extraordinary men'. Gender, Place \& Culture, 18, 45-63. doi: 10.1080/0966369X.2011.535299

The UFC (2012). Rules and regulations: Unified rules and other MMA regulations. [Online] Retrieved from http://www.ufc.com/discover/sport/rules-and-regulations

Theberge, N. \& Birrell, S. (1994). 'Structural constraints facing women in sport'. In D.M. Costa \& S.R. Guthrie (eds.) Women and Sport: Interdisciplinary Perspectives.

Champaign: Human Kinetics. pp.331-340

Theeboom, M. \& De Knop, P. (1999). Asian martial arts and approaches of instruction in physical education. European Journal of Physical Education, 4, 146-161. doi: 10.1080/1740898990040204

Theeboom, M., De Knop, P. and Vertonghen, V. (2009). Experiences of children in martial arts. European Journal for Sport and Society, 6, 19-35. Retrieved from http://www.ejss.ch/PDF-

Dateien/ejss2009_Vol6_Issue1_Theeboom\%20et\%20al_Experiences\%20of\%20children\% 20in\%20martial\%20arts.pdf

Twigger, R. (1997). Angry white pyjamas: A normal bloke becomes a deadly weapon. London: Phoenix 
Villamon, M., Brown, D., Espartero, J. \& Gutierrez, C. (2004). Reflexive modernization and the disembedding of judo from 1946 to the 2000 Sydney Olympics. International Review for the Sociology of Sport, 39, 139-156. doi: 10.1177/1012690204043458

Wacquant, L.J.D. (2004). Body \& soul: Notebooks of an apprentice boxer. Oxford: Oxford University Press

Wertheim, L.J. (2010). Blood in the cage: Mixed martial arts, Pat Miletich, and the furious rise of the UFC. New York: Mariner Books

Wetherell, M. \& Edley, N. (1999). Negotiating hegemonic masculinity: Imaginary positions and psycho-discursive practices. Feminism and Psychology, 9, 335-356. doi: $10.1177 / 0959353599009003012$

Woodward, K. (2004). Rumbles in the jungle: Boxing, racialization, and the performance of masculinity. Leisure Studies, 23, 5-17. doi: 10.1080/0261436042000182281

Wolf, T. (2005). The Bartitsu compendium, volume I: History and canonical syllabus. Raleigh, N.C.: Lulu 